\title{
Distinct roles of the Flil ATPase and proton motive force in bacterial flagellar protein export
}

\author{
Tohru Minamino $^{1,2}$ \& Keiichi Namba ${ }^{1,2}$
}

Translocation of many soluble proteins across cell membranes occurs in an ATPase-driven manner. For construction of the bacterial flagellum responsible for motility, most of the components are exported by the flagellar protein export apparatus ${ }^{1,2}$. The FliI ATPase is required for this export ${ }^{3}$, and its ATPase activity is regulated by $\mathrm{FliH}^{4}$; however, it is unclear how the chemical energy derived from ATP hydrolysis is used for the export process. Here we report that flagellar proteins of Salmonella enterica serovar Typhimurium are exported even in the absence of FliI. A fliH fliI double null mutant was weakly motile. Certain mutations in FlhA or FlhB, which form the core of the export gate, substantially improved protein export and motility of the double null mutant. Furthermore, proton motive force was essential for the export process. These results suggest that the FliH-FliI complex facilitates only the initial entry of export substrates into the gate, with the energy of ATP hydrolysis being used to disassemble and release the FliH-FliI complex from the protein about to be exported. The rest of the successive unfolding/translocation process of the substrates is driven by proton motive force.

The flagellar export apparatus consists of six integral membrane proteins (FlhA, FlhB, FliO, FliP, FliQ and FliR) and three soluble proteins (FliH, FliI and FliJ), and is thought to be located at the base of the flagellum ${ }^{1,2}$. Export of bacterial flagellar proteins has characteristics in common with the type III secretion system (T3SS) of virulence factors of pathogenic bacteria, and these two systems actually consist of many homologous component proteins ${ }^{5}$.

The soluble export component FliI is an ATPase ${ }^{3}$. Because mutants lacking the ATPase activity cannot export flagellar proteins, FliI was thought to convert chemical energy released by ATP hydrolysis into mechanical work necessary for the export ${ }^{3}$. FliI shows extensive similarity to the $\alpha / \beta$ subunits of proton-driven $\mathrm{F}_{0} \mathrm{~F}_{1}$-ATPase for its entire molecular structure ${ }^{6}$, although sequence similarity is limited to their respective ATPase domains ${ }^{7,8}$. Unlike $\mathrm{F}_{1}$-ATPase, however, which forms the $\alpha_{3} \beta_{3}$ hexameric ring, FliI self-assembles into a homohexamer ${ }^{9,10}$. When FliI oligomerization is suppressed by a small deletion in its amino-terminal region, flagellar protein export does not occur efficiently, suggesting that FliI hexamerizes on docking to the export gate made of the six integral membrane components, for which the cytoplasmic domains of FlhA and FlhB are thought to form the docking platform ${ }^{11}$. FliI binds to FlgN (chaperone) and to a FlgN-FlgK (HAP1) complex ${ }^{12}$, suggesting that FliI has a critical role in substrate recognition as well. As Salmonella InvC-a virulence T3SS homologue of FliI-binds to chaperone-effector complexes and induces chaperone release from, and unfolding of, the effector to be secreted in an ATPase-dependent manner ${ }^{13}$, FliI has been thought to act in a similar manner.

FliH binds to the extreme $\mathrm{N}$-terminal region of FliI to form the $\mathrm{FliH}_{2}$-FliI complex in the cytoplasm, and suppresses FliI oligomerization and ATPase activity ${ }^{4,8}$. However, as FliI cannot efficiently dock to the export gate when FliH is missing ${ }^{14}$, FliH is postulated to provide a link between ATP hydrolysis by FliI and flagellar protein export, although it is not known how this is done. We therefore investigated this by characterizing a Salmonella fliH fli double null mutant and by isolating gain-of-function mutants from this mutant.

A fliH null mutant was weakly motile whereas a fliI null mutant was non-motile ${ }^{14,15}$. Notably, when both FliH and FliI were missing (Fig. 1b, lane 4), the cells formed swarms on soft agar plates after prolonged incubation (Fig. 1a). Consistently, intact flagella as well as immature flagellar structures were occasionally observed by electron microscopy (data not shown). We then examined the effect of FlhB deletion, which makes wild-type cells non-motile (Fig. 1a). The motility of the double null mutant was totally abolished by a flhB::Tn 10 mutation (Fig. 1c), indicating that some flagella are produced at a low probability even in the absence of FliH and FliI, but in a manner that still requires FlhB. a

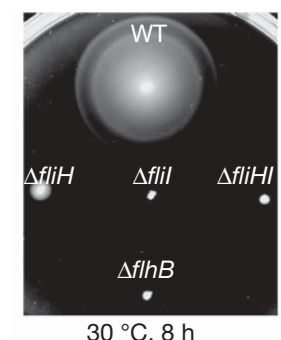

$30^{\circ} \mathrm{C}, 8 \mathrm{~h}$

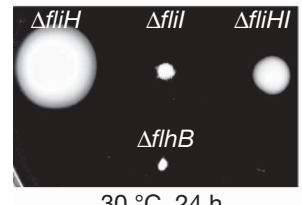

$30{ }^{\circ} \mathrm{C}, 24 \mathrm{~h}$

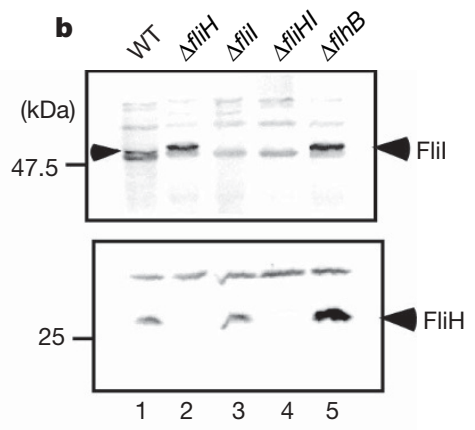

c

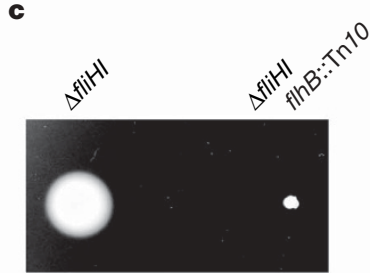

$30^{\circ} \mathrm{C}, 24 \mathrm{~h}$
Figure 1 | Characterization of a fliH flil double null mutant. a, Swarming motility of SJW1103 strain (wild type, WT), and MKM11 $(\Delta f l i H)$, MKM30 $(\Delta f l i)$, MMHI001 $(\Delta f l i H f l i I$, indicated as $\Delta f l i H I)$ and MKM50 $(\Delta f l h B)$ mutant strains on soft agar plates. $\mathbf{b}$, Immunoblotting, using anti-FliH and anti-Fli antibodies, of whole cell proteins. Weak bands just below those of FliI are due to nonspecific reactions. A slight downward shift of the FliI band in lane 1 is caused by an invisible band of a large amount of FliC $(51.5 \mathrm{kDa})$ just above it. c, Effect of a $f h B:: T n 10$ mutation on motility of the $\Delta f l i H f l i I$ mutant. 
FliH and FliI interact not only with FlhA and FlhB but also with flagellar chaperones such as FliJ and export substrates, leading to the proposal that the FliH-FliI complex is responsible for delivery of the substrates to the export gate $e^{4,11,12,14}$. To test this, gain-offunction mutants were isolated from the $\mathrm{fliH}$ fli double null mutant by streaking an overnight culture out on soft agar plates, incubating at $30{ }^{\circ} \mathrm{C}$ for 2 days and looking for motility haloes emerging from the streak. In total 22 pseudo-revertants were obtained. When we analysed the secretion of FliC (flagellin) into the culture supernatant by Coomassie brilliant blue staining, FliC was seen on SDSpolyacrylamide gel electrophoresis gels from the MMHI0117 strain, but not from the others (data not shown). Therefore, we decided to carry out further characterization of MMHI0117. The motility of MMHI0117 was significantly better than that of the parent mutant although not as good as that of wild type (Fig. 2a). Most cells of this strain had a couple of long flagellar filaments, whereas wild-type cells

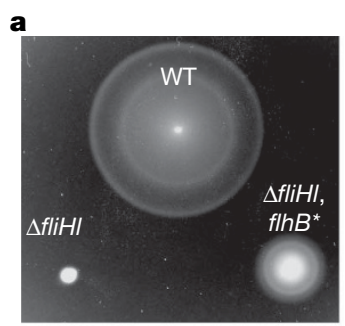

$30{ }^{\circ} \mathrm{C}, 8 \mathrm{~h}$
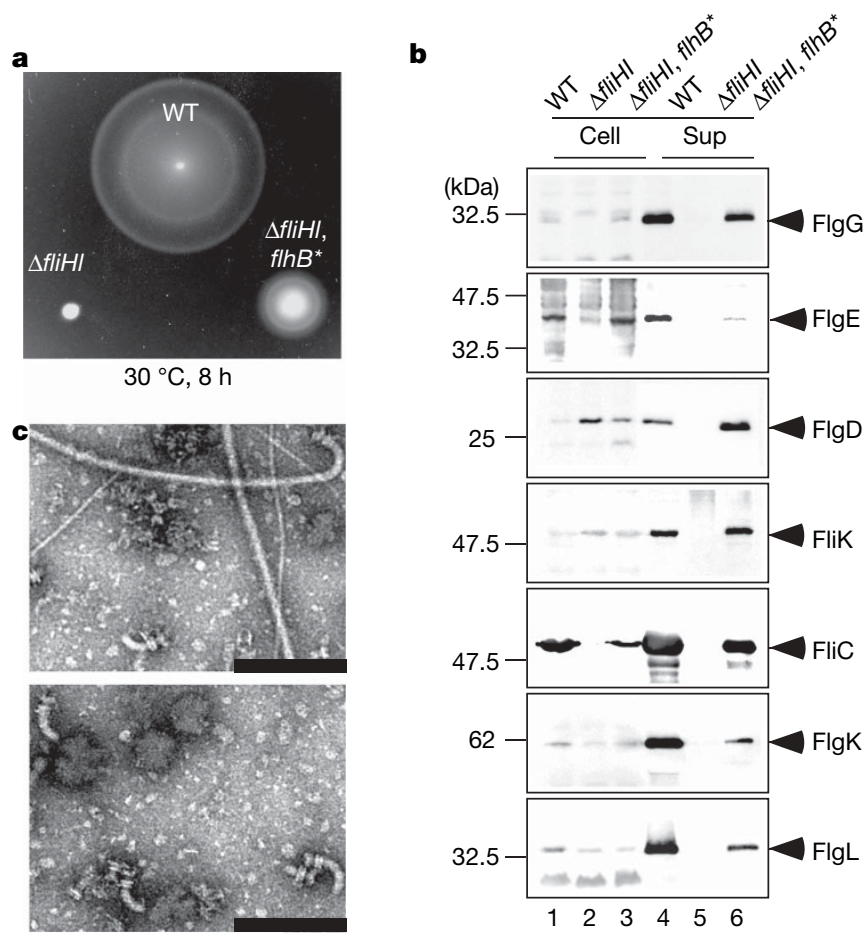

d
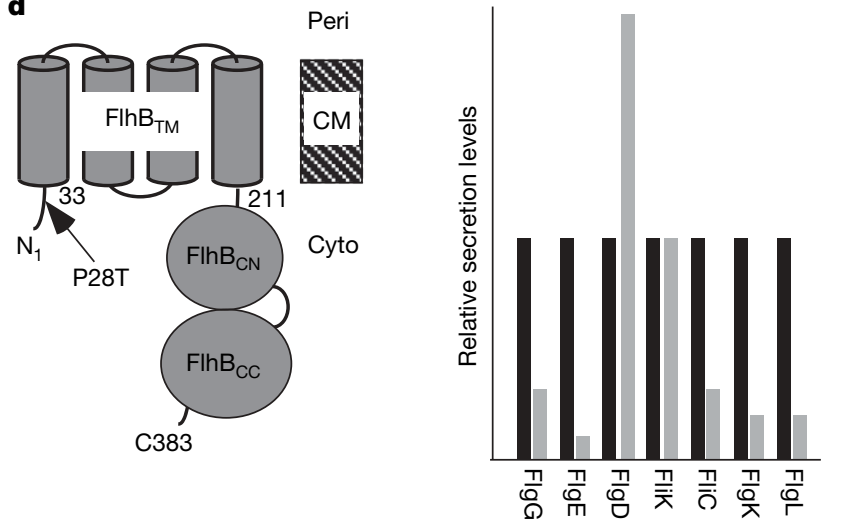

Figure 2 | Isolation of pseudo-revertants from the $\Delta$ fliH flil mutant. a, Motility of wild type, $\Delta f l i H f l i I$ mutant $(\Delta f l i H I)$ and its pseudo-revertant ( $\Delta$ fliH fliI, $f l h B(\mathrm{P} 28 \mathrm{~T})$, indicated as $\left.\Delta f l i H I, f l h B^{*}\right) . \mathbf{b}$, Secretion analysis of FlgG, FlgE, FlgD, FliK, FliC, FlgK and FlgL by immunoblotting. 'Cell' and 'Sup' indicate whole cell proteins and culture supernatant fractions, respectively. Relative secretion levels are normalized to the wild-type level of each protein. Black bar, wild type; grey bar, pseudo-revertant. c, Electron micrographs of the flagella and basal bodies isolated from $\Delta f l i H f l i I$, flhB(P28T). Scale bar, $200 \mathrm{~nm}$. d, Position of a suppressor mutation in FlhB. $\mathrm{CM}$, cytoplasmic membrane; cyto, cytoplasm; peri, periplasmic space. produce five or more (data not shown). Most flagellar proteins were detected in the culture supernatant of this mutant (Fig. 2b, lane 6). The amounts of FlgD (hook cap protein) and FliK (hook-length control protein) secreted by this pseudo-revertant were even larger than those of the wild type, whereas the secretion levels of FlgG (distal rod protein) and FlgE (hook protein) were threefold and tenfold lower than wild-type levels, respectively. Consistently, flagellar basal bodies, often with the hook and filament attached, were observed by electron microscopy (Fig. 2c). The secretion levels of these proteins were restored to wild-type levels by introduction of a plasmid encoding $\mathrm{FliH}$ and FliI into the mutant (Supplementary Fig. 1). These results indicate that the export of FlgE and FlgG depends on the FliH-FliI complex more strongly than the export of FlgD and FliK. As all of these proteins belong to the same rod-type and hook-type export class ${ }^{16}$, the FliH-FliI complex not only guides these proteins to the export gate but also controls their export order and levels. The cellular levels of FliC, FlgK and FlgL (HAP3) in the MMHI0117 strain were much lower than those in the wild type because expression of these genes occurs only after hook completion ${ }^{17}$, which is evidently retarded in this strain (Fig. 2b).

P22-mediated genetic mapping ${ }^{18}$ showed that the gain-of-function mutation lies in the flhBAE operon (data not shown). DNA sequencing identified a missense mutation, P28T, near the $\mathrm{N}$ terminus of FlhB, close to the interface with the first membrane span (Fig. 2d). The position of this P28T mutation was very close to the positions of the FliH-bypass $f l h B$ mutations isolated previously ${ }^{14}$. Therefore, we tested whether the FliH-bypass $f l h B$ and $f l h A$ mutations can improve motility of the fliH fliI double mutant. These mutations, as represented here by a flhA(V404M) mutation, considerably enhanced both motility and flagellar protein export (Supplementary Fig. 2), although their suppression abilities were much weaker than that of the $\operatorname{flh} B(\mathrm{P} 28 \mathrm{~T})$ mutation.

Salmonella T3SS virulence factors are secreted by the flagellar export apparatus in the absence of their chaperones ${ }^{19}$. As InvC and SsaN are the T3SS homologues of FliI in Salmonella ${ }^{20,21}$, there is a possibility that InvC and/or SsaN may complement the fliH fliI double null mutants for flagellar protein export, although SsaN is not expressed under our experimental condition ${ }^{21}$. However, this was ruled out by our observations that neither motility nor protein export of the pseudo-revertant was abolished by InvC or SsaN deletions (Supplementary Fig. 3). Therefore, we conclude that the gain-offunction mutations in FlhA and FlhB increase the probability of entry of flagellar proteins into the export gate, thereby increasing export efficiency. An increased gate-opening probability for higher efficiency of protein entry could be deleterious to the cells owing to leakage of small solutes. However, the growth of the mutants was normal (Supplementary Fig. 4a), suggesting that the export gate is not always open. It is likely that the interaction of export substrates with the gate, with or without the FliH-FliI complex, induces opening of the pore.

Unlike the $\mathrm{fliH}$ null and the fliH fliI double null mutants, the fliI null mutant was non-motile (Fig. 1a), indicating that FliH inhibits flagellar protein export in the absence of FliI. To test whether the $f l h B(\mathrm{P} 28 \mathrm{~T})$ mutation would also suppress the fliI null mutation, we analysed the motility of the pseudo-revertant transformed with a plasmid encoding FliH (Supplementary Fig. 5). The motility gained by the $f l h B(\mathrm{P} 28 \mathrm{~T})$ mutation was significantly suppressed, suggesting that the docking of free FliH to the FlhA-FlhB platform interferes with the entry of export substrates into the export gate, even in the presence of the $f l h B(\mathrm{P} 28 \mathrm{~T})$ mutation.

As it has been shown that Yersinia enterocolitica type III secretion is inhibited considerably by treatment with the protonophore carbonyl cyanide $m$-chlorophenylhydrazone $(\mathrm{CCCP})^{22}$, and that flagellar formation is also dependent on proton motive force $(P M F)^{23}$, we investigated whether flagellar protein export is still dependent on PMF in the gain-of-function mutant as well as wild-type cells. The rate of cell growth decreased when CCCP concentration increased, 
and $25 \mu \mathrm{M}$ CCCP immediately caused growth arrest (Supplementary Fig. 4b). As expected, the flagellar motor rotation, which is driven by the $\mathrm{PMF}^{1}$, was abolished by $25 \mu \mathrm{M}$ CCCP treatment, indicating that the PMF is significantly collapsed (data not shown). The intracellular levels of FlgD were maintained even at $25 \mu \mathrm{M}$ (Fig. 3); however, the levels of FlgD secretion by both wild-type and mutant cells decreased significantly above $10 \mu \mathrm{M}$ CCCP and diminished at $25 \mu \mathrm{M}$ (Fig. 3). In agreement with previous data ${ }^{22}$, the intracellular ATP level did not change on CCCP treatment within $1 \mathrm{~h}$ (Supplementary Fig. 4c). These results indicate that PMF is absolutely essential for FlgD export regardless of the presence or absence of FliH and FliI.

The MotA-MotB complex acts as a proton conductive pathway to couple proton influx with flagellar motor rotation ${ }^{1}$. Mutations in MotA or MotB do not affect flagellar formation while the motor is paralized ${ }^{1}$. Consistently, deletions of these two proteins do not interfere with flagellar protein export even in the gain-of-function mutant (data not shown).

Both ATP and PMF seem to be required for pre-protein translocation in Escherichia coli, where ATP is essential for the initial step of protein translocation and PMF increases the rate of translocation ${ }^{24}$. SecA is the ATPase that uses the energy of ATP binding and hydrolysis to drive pre-protein translocation into and across the cytoplasmic membrane ${ }^{24}$. Each catalytic cycle of SecA permits the stepwise translocation of pre-proteins across the membrane $e^{25,26}$. In contrast, we have shown that ATP hydrolysis by FliI is not absolutely required for flagellar protein export. As the diameter of the central channel of the flagellum - which is the export path for flagellar proteins - is only $2 \mathrm{~nm}^{27}$, proteins to be exported must be largely unfolded for entry into and translocation through the channel. Our observations-in particular, levels of FlgD and FliK secretion by a gain-of-function
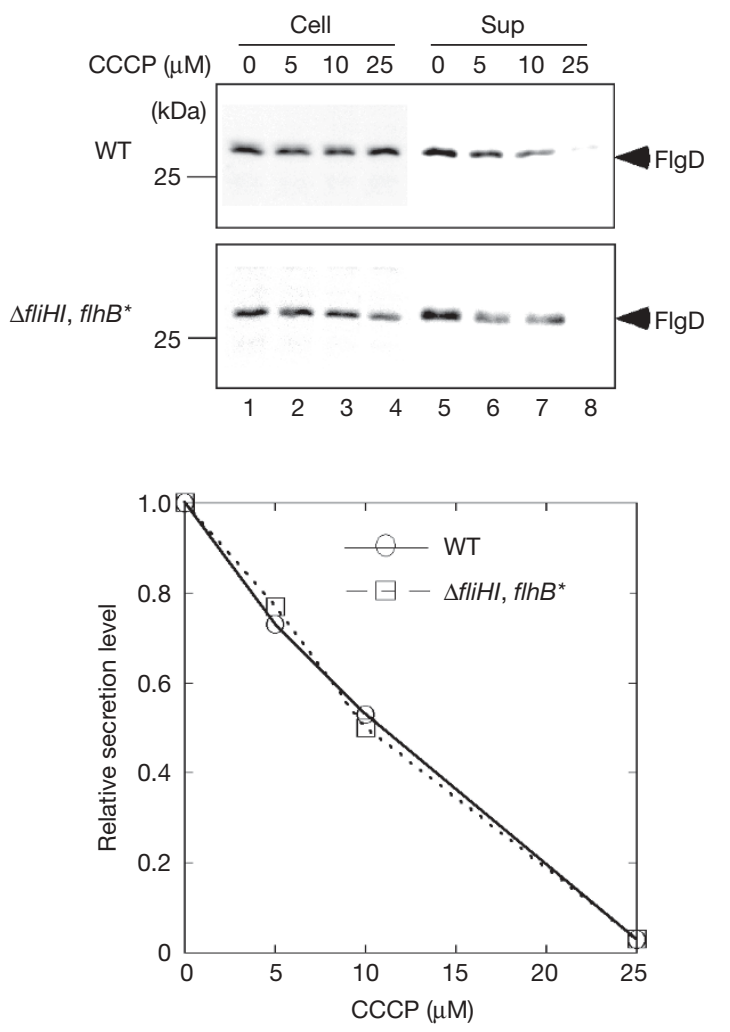

Figure 3 | Effect of CCCP on FlgD secretion. a, Immunoblotting, using the anti-FlgD antibody, of whole cell proteins and culture supernatant fractions prepared from wild-type (WT) and a gain-of-function mutant $(\Delta f l i H f l i I$, $\left.f l h B^{*}\right)$ grown at $30^{\circ} \mathrm{C}$ in the presence of $0,5,10$ and $25 \mu \mathrm{M} \mathrm{CCCP.} \mathbf{b}$, The decay in the secretion levels shown by plotting band densities of the two blots, which are normalized for the cellular FlgD levels. These data are the average of three independent experiments. The experimental errors are within $10 \%$. mutant that exceed wild-type levels (Fig. 2c)—suggest that the successive process of unfolding and translocation of export substrate is driven by PMF. The role of the FliH-FliI complex for efficient export would probably be to increase the initial docking efficiency of the $\mathrm{N}$-terminal segments of export substrates into the export gate through specific interactions between the $\mathrm{FliH}_{\mathrm{x}}-\mathrm{FliI}_{6}$ complex and the FlhA-FlhB platform. As the binding of the $\mathrm{FliH}_{\mathrm{x}}-\mathrm{FliI}_{6}$ complex without ATPase activity inhibits the export process ${ }^{4}$, the energy of ATP hydrolysis seems to be used to facilitate the release and disassembly of the $\mathrm{FliH}_{\mathrm{x}}-\mathrm{FliI}_{6}$ complex from the export gate and the protein about to be exported, in order for the subsequent PMFdriven, successive process of unfolding of the protein and translocation of the polypeptide chain through the gate by the export gate complex to proceed without retardation, as well as for efficient use of the $\mathrm{FliH}_{2}-$ FliI complexes for the next cycle of initial docking (Fig. 4). Because $\mathrm{N}$-terminal segments of export substrates containing export signals are all natively unfolded in the monomeric form of the proteins $^{28}$, the energy of ATP hydrolysis would not be required for the process of initial docking and entry to the gate.

Considering the many similarities between the flagellar export apparatus and $\mathrm{F}_{0} \mathrm{~F}_{1}$-ATPase, such as almost identical structures of
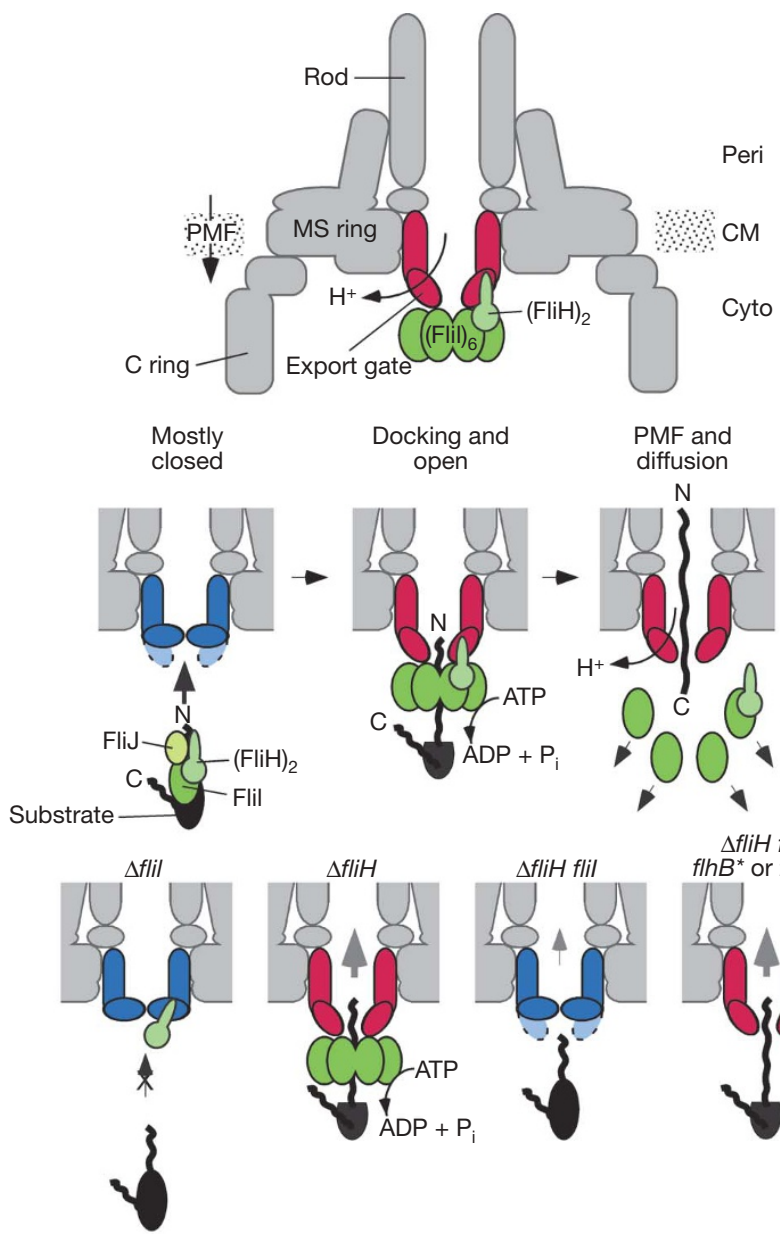

$\Delta$ fliH flil

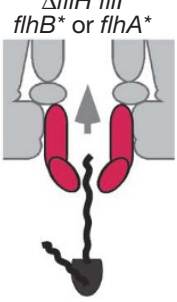

Figure 4 | Model for flagellar protein export. Top panel: The flagellar protein export apparatus in the basal body. Middle panel: in wild type, the $\mathrm{FliH}_{2}-\mathrm{FliI}$ complex delivers export substrates to the export gate along with FliJ (left). Once the N-terminal segment of a substrate is docked by formation of the $\mathrm{FliH}_{\mathrm{x}}-\mathrm{FliI}_{6}$ complex (middle), ATP hydrolysis induces dissociation of the $\mathrm{FliH}_{\mathrm{x}}-\mathrm{FliI}_{6}$ complex and successive unfolding and translocation of the substrates is driven by the PMF (right). Bottom panel: protein translocation is inhibited by $\mathrm{FliH}$ in the fliI mutant (left). The $f l i H$ mutant retains the export function to some extent (middle left). The fliH fliI double mutant also retains the export function, albeit at a low level (middle right). Gain-of-function mutations increase the efficiency of substrate entry (right). $\mathrm{P}_{\mathrm{i}}$, inorganic phosphate. 
FliI and the $\alpha / \beta$ subunits $^{6}$, the PMF-driven functions of the export gate and the $\mathrm{F}_{0}$ portion, and sequence/functional similarities between $\mathrm{FliH}$ and the $\delta / \mathrm{b}$ subunits ${ }^{29}$, these two remotely related systems may be similar to each other for their entire structural architectures.

\section{METHODS SUMMARY}

Salmonella strains and plasmids used in this study are listed in Supplementary Table 1. L-broth (LB) and soft tryptone agar plates were prepared as described ${ }^{30}$. Ampicillin and tetracycline were added as needed at a final concentration of $100 \mu \mathrm{g} \mathrm{ml}^{-1}$ and $15 \mu \mathrm{g} \mathrm{ml}^{-1}$, respectively. Motility assays were carried out on soft agar plates as described before ${ }^{4}$. Export assays were done as described previously $^{30}$.

The hook-basal bodies were purified and negatively stained with 3\% phosphotungstic acid ( $\mathrm{pH} 4.5)$ on carbon-coated copper grids. Micrographs were recorded at a magnification of $\times 25,000$ with a JEM-1011 transmission electron microscope (JEOL) operated at $100 \mathrm{kV}$.

The cellular levels of ATP were measured using the ATP bioluminescence assay kit CLS II as described previously ${ }^{22}$.

Full Methods and any associated references are available in the online version of the paper at www.nature.com/nature.

\section{Received 8 August; accepted 29 October 2007.}

1. Berg, H. C. The rotary motor of bacterial flagella. Annu. Rev. Biochem. 72, 19-54 (2003).

2. Minamino, T. \& Namba, K. Self-assembly and type III protein export of the bacterial flagellum. J. Mol. Microbiol. Biotechnol. 7, 5-17 (2004).

3. Fan, F. \& Macnab, R. M. Enzymatic characterization of Flil: an ATPase involved in flagellar assembly in Salmonella typhimurium. J. Biol. Chem. 271, 31981-31988 (1996).

4. Minamino, T. \& Macnab, R. M. FliH, a soluble component of the type III flagellar export apparatus of Salmonella, forms a complex with Flil and inhibits its ATPase activity. Mol. Microbiol. 37, 1494-1503 (2000).

5. Cornelis, G. R. The type III secretion injectisome. Nature Rev. Microbiol. 4, 811-825 (2006).

6. Imada, K., Minamino, T., Tahara, A. \& Namba, K. Structural similarity between the flagellar type III ATPase Flil and F1-ATPase subunits. Proc. Natl Acad. Sci. USA 104, 485-490 (2007).

7. Vogler, A. P., Homma, M., Irikura, V. M. \& Macnab, R. M. Salmonella typhimurium mutants defective in flagellar filament regrowth and sequence similarity of Flil to $\mathrm{F}_{\mathrm{O}} \mathrm{F}_{1}$, vacuolar, and archaebacterial ATPase subunits. J. Bacteriol. 173, 3564-3572 (1991).

8. Lane, M. C., O'Toole, P. W. \& Moore, S. A. Molecular basis of the interaction between the flagellar export proteins FliH and Flil from Helicobacter pylori. J. Biol. Chem. 281, 508-517 (2006).

9. Auvray, F., Ozin, A. J., Claret, L. \& Hughes, C. Intrinsic membrane targeting of the flagellar export ATPase Flil: Interaction with acidic phospholipids and FliH. J. Mol. Biol. 318, 941-950 (2002).

10. Claret, L., Susannah, C. R., Higgins, M. \& Hughes, C. Oligomerisation and activation of the Flil ATPase central to bacterial flagellum assembly. Mol. Microbiol. 48, 1349-1355 (2003).

11. Minamino, T. et al. Oligomerization of the bacterial flagellar ATPase Flil is controlled by its extreme N-terminal region. J. Mol. Biol. 360, 510-519 (2006).

12. Thomas, J., Stafford, G. P. \& Hughes, C. Docking of cytosolic chaperone-substrate complexes at the membrane ATPase during flagellar type III protein export. Proc. Natl Acad. Sci. USA 101, 3945-3950 (2004).

13. Akeda, Y. \& Galán, J. E. Chaperone release and unfolding of substrates in type III secretion. Nature 437, 911-915 (2005).
14. Minamino, T., González-Pedrajo, B., Kihara, M., Namba, K. \& Macnab, R. M. The ATPase Flil can interact with the type III flagellar protein export apparatus in the absence of its regulator FliH. J. Bacteriol. 185, 3983-3988 (2003).

15. González-Pedrajo, B., Fraser, G. M., Minamino, T. \& Macnab, R. M. Molecular dissection of Salmonella FliH, a regulator of the ATPase Flil and the type III flagellar protein export pathway. Mol. Microbiol. 45, 967-982 (2002).

16. Hirano, T., Minamino, T., Namba, K. \& Macnab, R. M. Substrate specificity classes and the recognition signal for Salmonella type III flagellar export. J. Bacteriol. 185, 2485-2492 (2003).

17. Kutsukake, K., Ohio, Y.\& lino, T. Transcriptional analysis of the flagellar region of Salmonella typhimurium. J. Bacteriol. 172, 741-747 (1990).

18. Yamaguchi, S., Fujita, H., Sugata, K., Taira, T. \& lino, T. Genetic analysis of H2, the structural gene for phase-2 flagellin in Salmonella. J. Gen. Microbiol. 130, 255-265 (1984).

19. Lee, S. H. \& Galán, J. E. Salmonella type III secretion-associated chaperones confer secretion-pathway specificity. Mol. Microbiol. 51, 483-495 (2004).

20. Eichelberg, K., Ginocchio, C. C. \& Galán, J. E. Molecular and functional characterization of Salmonella typhimurium invasion genes invB and invC: homology of InvC of the $F_{0} F_{1}$ ATPase family of proteins. J. Bacteriol. 176, 4501-4510 (1994).

21. Deiwick, J., Nikolaus, T., Erdogan, S. \& Hensel, M. Environmental regulation of Salmonella pathogenicity island 2 gene expression. Mol. Microbiol. 31, 1759-1773 (1999).

22. Wilharm, G. et al. Yersinia enterocolitica Type III secretion depends on the proton motive force but not on the flagellar motor components MotA and MotB. Infect. Immun. 72, 4004-4009 (2004).

23. Galperin, M. Y., Dibrov, P. A. \& Glagolev, A. N. $\mu \mathrm{H}+$ is required for flagellar growth in Escherichia coli. FEBS Lett. 143, 319-322 (1982).

24. Mori, H. \& Ito, K. The Sec protein-translocation pathway. Trends Microbiol. 9, 494-500 (2001).

25. Schiebel, E., Driessen, A. J. M., Hartl, F.-U. \& Wickner, W. $\Delta \mu \mathrm{H}$ and ATP function at different steps of the catalytic cycle of preprotein translocase. Cell 64, 927-939 (1991).

26. van der Wolk, J. P., de Wit, J. G. \& Driessen, A. J. The catalytic cycle of the Escherichia coli SecA ATPase comprises two distinct preprotein translocation events. EMBO J. 16, 7297-7304 (1997).

27. Yonekura, K., Maki-Yonekura, S. \& Namba, K. Complete atomic model of the bacterial flagellar filament electron cryomicroscopy. Nature 424, 643-650 (2003).

28. Namba, K. Roles of partly unfolded conformations in macromolecular selfassembly. Genes Cells 6, 1-12 (2001).

29. Pallen, M. J., Bailey, C. M. \& Beatson, S. A. Evolutionary links between $\mathrm{FliH} / \mathrm{YscL}$-like proteins from bacterial type III secretion systems and second-stalk components of the $\mathrm{F}_{\mathrm{o}} \mathrm{F}_{1}$ and vacuolar ATPases. Protein Sci. 15, 935-941 (2006).

30. Minamino, T. \& Macnab, R. M. Components of the Salmonella flagellar export apparatus and classification of export substrates. J. Bacteriol. 181, 1388-1394 (1999).

Supplementary Information is linked to the online version of the paper at www.nature.com/nature.

Acknowledgements We thank A. Blocker, A. Veenendaal and K. Imada for critical reading of the manuscript and comments; N. Moriya, S. Nakamura and K.-I. Kazetani for technical help; K. Hughes for a gift of an ssaN::tetRA allele; and M. Macnab and F. Oosawa for continuous support and encouragement. This work was partially supported by Grants-in-Aid for Scientific Research from the Ministry of Education, Culture, Sports, Science and Technology of Japan to T.M. and K.N.

Author Information Reprints and permissions information is available at www.nature.com/reprints. Correspondence and requests for materials should be addressed to K.N. (keiichi@fbs.osaka-u.ac.jp). 


\section{METHODS}

Transductional crosses and DNA manipulations. P22-mediated transductional crosses were carried out with p22HTint ${ }^{18}$. DNA manipulations were carried out as described before ${ }^{4}$.

Motility assay. Fresh colonies were inoculated on soft tryptone agar plates and incubated at $30^{\circ} \mathrm{C}$.

Export assay. Whole cells and culture supernatant fractions were prepared from Salmonella cells grown at $30^{\circ} \mathrm{C}$ in $\mathrm{LB}$, as described previously ${ }^{30}$.

To test the effect of CCCP on flagellar protein export, the cells were grown with shaking in $5 \mathrm{ml}$ of $\mathrm{LB}$ at $30{ }^{\circ} \mathrm{C}$ until the cell density had reached an optical density at $600 \mathrm{~nm}\left(\mathrm{OD}_{600}\right)$ of approximately 0.6-0.7. After washing twice with $\mathrm{LB}$, the cells were re-suspended in $5 \mathrm{ml} \mathrm{LB}$ with or without CCCP and incubated at $30{ }^{\circ} \mathrm{C}$ for $1 \mathrm{~h}$. Cultures were centrifuged to obtain the cell pellets and culture supernatants. Cell pellets were re-suspended in the SDS-loading buffer, and normalized to a cell density to give a constant amount of cells. Proteins in the culture supernatants were precipitated by $10 \%$ trichloroacetic acid, suspended in the Tris/SDS loading buffer and heated at $95^{\circ} \mathrm{C}$ for $5 \mathrm{~min}$.

Immunoblotting with polyclonal anti-FlgG, anti-FlgD, anti-FlgE, anti-FlgK, anti-FlgL, anti-FliK, anti-FliC, anti-FliH and anti-FliI antibodies was carried out as described before ${ }^{30}$. Detection was performed with an ECL plus immunoblotting detection kit (GE Healthcare).

Preparation of the hook-basal bodies. The hook-basal bodies were prepared as described previously ${ }^{31}$ with minor modifications. Samples were negatively stained with $3 \%$ phosphotungstic acid ( $\mathrm{pH} 4.5)$ on carbon-coated copper grids. Micrographs were recorded at a magnification of $\times 25,000$ with a JEM-1011 transmission electron microscope (JEOL) operated at $100 \mathrm{kV}$.

Construction of a $\Delta i n v C:$ :tetRA strain. An invC null strain $(\Delta i n v C:$ :tetRA) was constructed using the $\lambda$ Red homologous recombination system, as described before ${ }^{32-34}$.

Measurement of intracellular ATP levels. The cellular levels of ATP were measured using the ATP bioluminescence assay kit CLS II (Roche) as described previously $^{22}$. Cultures, $1.5 \mathrm{ml}$ each, were centrifuged, and the pellets were resuspended in $100 \mathrm{mM}$ Tris- $\mathrm{HCl} \mathrm{pH} 7.75,4 \mathrm{mM}$ EDTA, with adjustment of the $\mathrm{OD}_{600}$ of the cell suspensions to 1.0. The cell suspensions, $300 \mu \mathrm{l}$ each, were boiled for $2 \mathrm{~min}$ at $100^{\circ} \mathrm{C}$. Samples were centrifuged, and $100 \mu \mathrm{l}$ of each supernatant was transferred to a microtitre plate that was kept on ice until measurement. A $100 \mu \mathrm{l}$ solution of luciferase reagent was added and then bioluminescence was detected by a LAS-3000 luminescent image analyser (Fujifilm).

31. Aizawa, S.-I., Dean, G. E., Jones, C. J., Macnab, R. M. \& Yamaguchi, S. Purification and characterization of the flagellar hook-basal body complex of Salmonella typhimurium. J. Bacteriol. 161, 836-849 (1985).

32. Datsenko, K. A. \& Wanner, B. L. One-step inactivation of chromosomal genes in Escherichia coli K-12 using PCR products. Proc. Natl Acad. Sci. USA 97, 6640-6645 (2000).

33. Aldridge, P., Karlinsey, J. E. \& Hughes, K. T. The type III secretion chaperone FlgN regulates flagellar assembly via a negative feedback loop containing its chaperone substrates FlgK and FlgL. Mol. Microbiol. 49, 1333-1345 (2003).

34. Karlinsey, J. E. \& Hughes, K. T. Genetic transplantation: Salmonella enterica serovar Typhimurium as a host to study sigma factor and anti-sigma factor interactions in genetically intractable systems. J. Bacteriol. 188, 103-114 (2006). 